\title{
IMPORTANCIA Y VALORES SOBRE LA SALUD MENTAL EN «EL MÉDICO INGLÉS», DE RICARDO PALMA
}

\section{Importance and values on mental health in Ricardo Palma's «El médico inglés»}

DEISY ALEJANDRA ESQUIVEL RONCEROS

Facultad de Psicología, Universidad Ricardo Palma

Lima, Perú

Contacto: deisy.esquivel@urp.edu.pe

\section{RESUMEN}

Este artículo tiene como propósito analizar la salud mental en el Perú a partir del siglo XIX y compararla con la actualidad ante la llegada de la pandemia de la COVID-19. A su vez, se busca informar sobre cómo la falta de intervención de algún especialista en el área mental y social, lleva al ciudadano a un declive en su personalidad. En efecto, a puertas del bicentenario debería lograrse un óptimo bienestar emocional, psicológico y social gracias a la atención en la salud mental de cada peruano. Ello no es así debido a la herencia colonial que llevamos aún presente y que abarca nuestra esclavitud en la marginalidad, el rechazo y el egoísmo, que deteriora nuestras creencias y acciones. Por este motivo se toma la tradición «El médico inglés», de Ricardo Palma, para resaltar la preocupación por una atención médica eficaz, más allá de la salud física. 
Palabras clave: Tradiciones peruanas; salud mental; bienestar; pandemia; herencia colonial.

\section{ABSTRACT}

The purpose of this article is to analyse mental health in Peru from the 19th century onwards and to compare it with the current situation in the face of the arrival of the COVID-19 pandemic. At the same time, it seeks to report on how the lack of intervention by a specialist in the mental and social area leads citizens to a decline in their personality. Indeed, on the eve of the bicentenary, optimal emotional, psychological and social well-being should be achieved through attention to the mental health of every Peruvian. This is not the case due to the colonial heritage we still carry with us, which includes our slavery to marginality, rejection and selfishness, which deteriorates our beliefs and actions. For this reason, the story of Ricardo Palma's «El médico inglés» is taken to highlight the concern for effective medical care, beyond physical health.

Key words: Tradiciones peruanas; Ricardo Palma; mental health; wellness; pandemic; colonial heritage.

Recibido: 13/11/2020 Aceptado: 15/12/2020 


\section{INTRODUCCIÓN}

En principio, la Ley del Trabajo del Psicólogo (Ley n. ${ }^{\circ}$ 28369) señala que el psicólogo es el profesional de la conducta humana, cuya función es la prevención, el tratamiento, el diagnóstico, la promoción y la recuperación de la salud mental. Según la Organización Mundial de la Salud (OMS), esta última se define como un estado de bienestar donde el individuo es consciente de sus capacidades, afronta las tensiones de la vida y, a su vez, trabaja productivamente tanto en el ámbito laboral como en la comunidad; además, dicho bienestar implica la búsqueda de sentido y armonía, de una óptima capacidad de autocuidado, empatía, confianza y el reconocimiento de sus derechos, según la Ley de Salud Mental peruana.

En el ser humano, el componente psicológico con respecto a la salud mental, empieza desde lo interior, el sistema nervioso, cuya reacción y conexión de los neurotransmisores procura una correcta sinapsis. En caso contrario, la segregación acelerada e incontrolada de hormonas u otro problema fisiológico, traerá consigo efectos en lo exterior de la persona: en el componente físico, un desorden emocional; en cuanto a lo cognitivo, cambios de pensamiento y actitudes, incluso la llegada de enfermedades como la depresión o trastornos como la bipolaridad de la personalidad. El componente social, por otro lado, se asocia al ambiente, la familia, la educación, el trabajo, etc., lo que va configurando la imagen propia y de los demás.

Cada peruano presenta un mestizaje histórico de influencias raciales, sociales y culturales. La mayor parte de la población, como señalan Aramburú y Mendoza (2015), se centra en la capital, ante las migraciones del pasado. Los migrantes traen desde sus regiones natales su legado, que se ha vivido de manera tormentosa por siglos ante el cargo de líderes y gobernantes posteriores a la Conquista, la Colonia, el Virreinato, la República, y marcando el antes 
y el después de la independencia. La patología política provocará la pérdida de la credibilidad, sobre todo la desconfianza en el gobierno, las instituciones públicas, los partidos políticos e incluso en el propio ciudadano, haciéndole sentir a este el abandono, la exclusión, la devaluación, peor aún con la descalificación de su lengua materna.

Ante esto, la patología política se explica, vista desde la corrupción, con un enfoque patológico mental, social, político y ético, cuyo resultado es una persona con carácter obsesivo-compulsivo, que busca encontrar ganancias en su periodo de gobierno, pues presenta odio, angustia, estrés. Es supersticiosa, inmediatista y estratégicamente superficial, al procurar estar enterada de todos los pasos de cada persona, busca trascendencer, desde su comunicación social, es decir, con sus oyentes (seguidores de su partido político y ciudadanos en general), principalmente los de clase media o baja. Aquí suelen participar notables figuras de la más alta clase.

$\mathrm{Al}$ enfrentar algún movimiento de masas o de otros líderes, los políticos pretenden llegar al público con la proclamada igualdad social y tensionar el capitalismo. Son conscientes de la mala impresión que causan sus conductas y actitudes, incluso sus pronunciamientos negativos y críticos, su incapacidad de sentir empatía con el entorno y su avidez de dinero y poder. Para estas personas el fin justifica los medios, confunden legitimidad con preparación y creen que los votos obtenidos por el partido son un apoyo directo de los ciudadanos a su persona, hasta llegan a convencerse de que tienen la verdad en sus manos.

Además, llegan a vanagloriarse de manera exagerada tras su excesiva confianza, presentan un alejamiento progresivo de la realidad, al tomar decisiones precipitadas y poco meditadas, por su capacidad intelectual limitada. Como consecuencia, tienen poca valentía para dar la cara y suelen comprar voluntades, recurren al 
victimismo cuando hablan de ellos, de sus orígenes, y lo utilizan como un mérito propio, al confundir la legitimidad democrática ante el deterioro progresivo social; tras su afán desmedido por engañar, prometer, falsificar con falsos argumentos, el resultado será el proceso degenerativo de la personalidad, con un furor incontenible de amor a sí mismo, inmoralidad, esto es, una patología corporativa que demanda obediencia y asentimiento.

El psicólogo Jorge Yamamoto afirma que la mayoría de peruanos tienen problemas de comportamiento y divide a los peruanos en tipos: «el peruano super precavido, una persona hiperreactiva al temor, con mucha ansiedad y que en su desarrollo aprendió a bajar la ansiedad con conductas de sobreprotección. En el caso del peruano antisocial, hay una tendencia genética y que ha podido ser víctima de maltrato psicológico, físico» (Valdivia, 2020, párr. 2). Este último siempre encuentra una justificación para no acatar la norma, y busca como representantes a personas con esta patología política.

Sin embargo, cabe resaltar que no toda persona que ejerce el poder lo hace desde una patología del poder, pues existe el liderazgo natural que lleva al ejercicio de una autoridad en servicio de la comunidad y de sus grandes ideales y propósitos. Ante esto los políticos deben ser conscientes de que son gestores temporales de lo público y no perder el contacto con la realidad ni con los ciudadanos, pues deben demostrar vocación de servicio.

Para entender la personalidad peruana, esta se debe abordar de manera multidisciplinaria, pues involucra su estilo de vida, desde lo ambiental y geográfico, también lo lingüístico, el nivel socioeconómico y educacional. Comenzando por la clasificación de Basadre (1958) en La promesa de la vida peruana y otros ensayos, en la que da cuenta de los podridos, quienes ensucian, manipulan, alteran las palabras, conceptos, hechos e instituciones en la práctica del diálogo, discurso y leyes para sus propios beneficios y logran así la mediocridad del 
país; luego están los congelados, grupo exclusivo que solo atiende a sus iguales, cuyo poder no es grato a cualquiera; y, por último, los incendiados, cuyas acciones quedan en lo lejano, dejándonos solo la promesa hecha falacia.

Entonces, estos personajes tienen un déficit de sentido afectivo, ético e intelectual. Puede decirse también que tienen un desorden de la personalidad antisocial, según el DSM-5, por su carencia de empatía, desapego de las normas sociales, tendencia a la falta de culpa y vergüenza. A manera de síntesis, una fácil interpretación nos lleva a la corrupción, el narcotráfico, la delincuencia, el contrabando, el terrorismo, etc., que se albergan en las entidades más importantes y hasta en los ciudadanos mismos. Es claro que esto es un trastorno de la personalidad, lo cual es un problema grave reflejado en la salud mental, pues según Martha Stout (2006), autora del libro The Sociopath Next Door, 1 de cada 25 personas es sociópata, y estima que alrededor del $5 \%$ de la población lo padece.

Y es que la sociopatía es un trastorno de personalidad antisocial, que consiste en que las personas pierden la importancia de las normas sociales; por ello, no respetan las leyes, les cuesta adaptarse a los grupos. Al respecto, el doctor Carlos Vera Scamarone, psiquiatra del Hospital III de Emergencias Grau de la Red Desconcentrada Almenara de EsSalud, señala que los estudios de imágenes en resonancia magnética funcional muestran que los sociópatas tienen dificultad para manifestar empatía, por la disminución de las conexiones entre el sistema emocional y el procesamiento de la información, manifestados desde la niñez como síntomas, pero no pueden ser diagnosticados hasta la adolescencia o edad adulta.

Está demostrado que ello viene en la carga genética, ya que se asocia a las conductas de violencia, ruptura de la ley y poder, como el caso de los mandatos morales que permiten la vida social para conseguir determinados objetivos. Si el acto inmoral se convierte en un problema, 
si es descubierto y trae consecuencias, buscan maneras de minimizar el problema o salir con nuevas mentiras, pues el remordimiento o la culpa sincera no son parte de su personalidad, por ser egocéntricos; se perciben como personas impecables y como buenos observadores, capturan fácilmente las debilidades de otros para usarlas a su favor, por lo que los usan o los destruyen, según lo que les convenga, es así que ocupan puestos directivos, dirigidos hacia una meta específica (dinero, posición, poder). Actúan manipuladoramente, al ser hábiles mostrando excusas para librarse de la ley, buscan situaciones de poder, muestran un encanto y seducción superficial para conseguir sus objetivos, poseen un gran ego, llegan a vanagloriarse de las situaciones y buscan controlar las acciones y emociones de los demás. Aunque pueden llegar a ser desconfiados, pues son conscientes de lo que hacen y de que pueden generar conflictos. Incluso algunos buscan una relación de dependencia emocional donde asumen el dominio, mediante la humillación crean situaciones en las cuales tienen el poder, obligando a la persona subordinada a realizar algo que no desea.

Por ello, el psicólogo social Jorge Yamamoto afirma que siempre encuentran una justificación para transgredir la norma. Ante esto, en cuanto a las reacciones en su conducta frente a la pandemia, se encontró un peruano «super prevenido, que está encerrado en su casa [...] que se considera cuidadoso, respetuoso de las normas» (Valdivia, 2020, párr. 2); «el peruano resistente al cambio, con un nivel bajo de conciencia $[. .$.$] al no darse cuenta de las consecuencias de su conducta$ [...] [que] sigue con su rutina» (Valdivia, 2020, párr. 3). Por último, el peruano "que reta a la autoridad, que no cree en nadie» (Valdivia, 2020, párr. 3). Al ubicarse en los extremos, por su mal carácter, por su tendencia genética de nacimiento que ha sido reforzada durante la niñez y la adolescencia, reacciona tarde a la norma.

Decirle al peruano que cada uno se cuide, que depende de sí mismo y de su compromiso, provocó un mal uso de su libertad, a su 
conveniencia. Se olvidó de lo bueno que tiene, al solo enfocarse en lo negativo. Así, se siente desafiante, invulnerable y soberbio frente a las normas dispuestas para contener el avance, la aceptación del distanciamiento social, el uso de la mascarilla, el lavado de manos, el evitar el transporte público abarrotado, las fiestas clandestinas, las despedidas tumultuosas de seres queridos, etc., se volvió rebelde, con actitudes desafiantes ante la autoridad de los padres, de la policía y otras instancias, muchos de ellos con rasgos de comportamiento antisocial procedentes de familias problemáticas.

Conviene enfatizar que en el momento en que la sociedad incumple el orden social imperante, provoca un caos que inhibe la posibilidad de consensuar ajustes de dirección en las decisiones del poder, lo cual trae desesperanza; desigualdades políticas, sociales y económicas; corrupción e injusticia; modifica el carácter de la sociedad y origina patrones de conducta sociópata. Así pues, el estudio realizado a 1578 adultos de entre 18 y 73 años, para evaluar sus rasgos de personalidad desadaptativos y su actitud hacia las normas contra la COVID-19, por la revista Personality and Individual Differences, señala que los ciudadanos con rasgos antisociales tienen más probabilidades de ignorar o minimizar los riesgos que puede ocasionar y esto los lleva a tomar una actitud negativa ante las medidas sanitarias.

En definitiva, se recomienda las terapias cognitivo-conductuales para un control sobre los pensamientos que conducen a acciones ilegales, que contribuyen a una disminución en la aparición de conductas antisociales, puesto que se requiere un enfoque individual para el trastorno disocial, para que la persona que lo padece tenga tolerancia con el entorno cercano y los mecanismos de ajuste en la sociedad, al identificar la causa que ha provocado la sociopatía, apoyado de terapias familiares y grupales, a fin de que piense en las necesidades y los sentimientos de los demás. Además, es necesario 
el uso de medicamentos para aliviar a los concomitantes, síntoma común de un trastorno de personalidad disocial, y la prescripción de antidepresivos.

La relación entre los rasgos antisociales y el cumplimiento de las medidas de contención de la COVID-19 muestra los niveles más bajos de empatía, los niveles más altos de insensibilidad, la tendencia al engaño y los comportamientos de riesgo, tras emplear relaciones utilitarias, es decir, únicamente se vinculan con los demás cuando pueden obtener un beneficio. El trastorno antisocial de la personalidad tiene como característica el desprecio de los derechos de los demás por la búsqueda constante de satisfacción personal, al no sentir temor ante la amenaza del castigo, así como buscar emociones sin consideración de los posibles riesgos. El marcado narcisismo de las personas con este trastorno orienta su conducta en función de sus propios intereses, su sobrevaloración se expresa en una manía y en su capacidad para conseguir sus objetivos.

También son vistas como personas simpáticas, seductoras, hábiles en manipular a otros para su beneficio personal. Cabe resaltar que no tienen alteraciones en el pensamiento lógico formal, pero no tienen límites en el uso de su inteligencia para la satisfacción inmediata de sus deseos; en cuanto a sus progresos, estos se dan en el desarrollo cognitivo, para adquirir y elaborar sus propias teorías, así los psicópatas tienden a crear códigos propios de comportamiento, construyen su propia moral y a partir de la racionalización de su conducta, justifican y empoderan su delito. Esto significa que su comportamiento es adaptativo y pasa inadvertido para las demás personas. A nivel neurológico, las neuronas espejo, relacionadas con la capacidad de empatía, se encuentran ausentes en el lóbulo prefrontal del cerebro, pues se ha escindido la razón de los sentimientos. 
En efecto, ello proviene de la falta de control en la educación, atención en la salud pública, una economía estable y el conocimiento de la realidad nacional, que expone a situaciones deplorables y a posibles sentimientos de venganza y revancha a los marginados, ante la inacción de sus representantes indiferentes. Este círculo vicioso del mal repercute en ambos, lo cual se muestra en su personalidad. Por ello, se da un enfrentamiento de dilemas éticos y encubrimientos a lo largo de la historia, la incomprensión de la violencia, la crisis de identidad, los complejos de culpa, manteniendo las ideas negativas, falta de diálogo interno y externo, pues los residuos desde la conquista hasta nuestra actual república han determinado que el peruano viva espacios de sometimiento.

El Instituto Nacional de Salud Mental Honorio Delgado-Hideyo Noguchi (2002-2010) detalla que el acceso al tratamiento es del $80 \%$, en otras palabras, 8 de cada 10 personas con un trastorno mental o necesitados de atención no reciben el tratamiento correspondiente, la mayoría se encuentra en situación de pobreza (Enterarse, 2019, «¿Cuál es la situación mental en el Perú?», párr. 3).

En el periodo 2013-2016, el Banco Mundial realizó un estudio donde el Perú registraba 700 psiquiatras, ubicados el 80 \% en Lima. El $50 \%$ trabajaba en el sector privado, mientras que el $20 \%$ de los psiquiatras eran empleados por el Ministerio de Salud, en hospitales generales. Por lo cual en el 2017 había solo 13 centros con unidades de hospitalización de salud mental en 9 regiones del país (Enterarse, 2019, «¿Cuántos profesionales y establecimientos de salud mental hay en el Perú?», párr. 1).

Asimismo, en el 2018 el Ministerio de Salud asegura que se llegó a tener 152 centros de salud mental comunitarios implementados; además, de acuerdo con el «Plan nacional de fortalecimiento de servicios de salud mental comunitaria», "se requieren 281 centros de salud mental comunitaria del Ministerio de Salud» (Enterarse, 
2019, «¿Cuántos profesionales y establecimientos de salud mental hay en el Perú?», párr. 2). En relación con el informe «El derecho a la salud mental», publicado por la Defensoría del Pueblo (2019), hubo 4514781 personas con problemas de salud mental, es decir, un $15 \%$ de la población peruana; se proyecta al 2021 un estimado de 4659 253 peruanos más, aumentando la cifra en $3.2 \%$. En consecuencia, prevalecen los trastornos mentales a nivel nacional hasta un $33.7 \%$, poniendo en superficie que 1 de cada 3 peruanos tendrá algún problema de salud mental en algún momento.

En tanto, el informe «La carga de los trastornos mentales en la Región de las Américas, 2018», de la Organización Panamericana de la Salud (OPS), revela que el gasto de servicios de salud mental a nivel mundial es del $2.8 \%$ del total del presupuesto del gasto para el sector salud. En América, oscila entre el $0.2 \%$ de Bolivia y el $8.6 \%$ de Surinam. Así, la Organización Mundial de la Salud informa que para tener una adecuada atención mental, el país con ingresos medios debería gastar entre US\$3 y US $\$ 4$ por habitante, un promedio general entre S/ 308312990 y S/ 499798 160, en contraste con el Ministerio de Economía que en el año 2018 invirtió cerca de S/ 200831110 en control de prevención y salud mental. Ante ello, el Minsa necesita entre el $5 \%$ y el $15 \%$ del presupuesto nacional para salud mental, pues su presupuesto destinado es apenas el $0.1 \%$ del presupuesto nacional y el $1 \%$ del presupuesto del sector salud.

La OPS comparó el porcentaje de los problemas de salud mental con el del gasto destinado, y en América, el porcentaje de problemas de salud mental es seis veces mayor a la proporción de fondos asignados a salud mental. En Perú, el problema de salud mental es 6.4 veces mayor. Por otro lado, en América del Sur hay aproximadamente 6 psiquiatras por cada 100 mil habitantes; y en América del Norte, 9 psiquiatras por cada 100 mil habitantes. En Perú hay alrededor de 3 psiquiatras por cada 100 mil habitantes y 9 psicólogos por cada 100 mil habitantes. 
El promedio de América del Sur es 50.53 y el de América del Norte es 28 por 100 mil habitantes. Un $15 \%$ de peruanos tenía un problema de salud mental, y de acuerdo con la Defensoría del Pueblo (2019), se trataría de más de 4 millones de personas, es decir, 8 de cada 10 peruanos no recibirían un tratamiento adecuado.

En el 2020, la COVID-19 y el distanciamiento social impactó en la salud mental, sobre todo en los cambios emocionales. El $40 \%$ de la población mostró cuadros de ansiedad. Ello fue señalado por el registro de la línea telefónica 113, opción 5; el mayor número de llamadas presentaba síntomas físicos como dolor de cabeza, opresión en el pecho, problemas gastrointestinales, como diarrea o estreñimiento. Sin embargo, se hace presente el trastorno de estrés postraumático, hipocondría, obsesión por la limpieza, trastorno obsesivo compulsivo, ante la experiencia de efectos traumáticos, naturales o ambientales en el pasado. El Minsa y la OPS estiman que 7 de cada 10 peruanos estarían sufriendo algún tipo de problema o sintomatología en su salud mental, sobre todo personas mayores, al tener dificultades para dormir (55.7\%), problemas con el apetito (42.8\%), falta de energía (44\%) y concentración (35.5\%) e ideaciones suicidas (13.1\%) (Andina, 2020a, párrs. 10-11).

En julio el Minsa previó la implementación de 47 nuevos Centros de Salud Mental Comunitarios y el fortalecimiento de los 152 existentes, con la finalidad de garantizar la atención de la salud mental, sobre todo en Ayacucho, la región con mayor prevalencia de trastornos mentales en Perú. Junto con la Organización Panamericana de la Salud (OPS) se llegó a señalar que 6 u 8 de cada 10 peruanos estarían sufriendo algún tipo de problema o sintomatología relacionada con enfermedades de salud mental, es decir, cerca del $15 \%$ de los peruanos. Por fin se dio gasto necesario para la implementación de los centros en beneficio de los ciudadanos, igual que aquel médico inglés «Decíase que sin recibir 
de nadie una moneda en pago, ejercía la medicina con los pobres indios, realizando en ellos curaciones» (Palma, 2006, p. 101).

Por otro lado, en octubre, por el Día Mundial de la Salud Mental, se formó el proyecto Anímate Perú, cuyo propósito es fortalecer los servicios de salud mental en los distritos de Lima Sur, según afirmó el director general del Instituto Nacional de Salud Mental Honorio Delgado-Hideyo Noguchi, quien además indicó que se implementará un sistema electrónico compartido de soporte a los procesos de admisión, gestión de citas, programación y registro de datos clínicos. Añadió, asimismo, que se formó un convenio de cooperación interinstitucional el 21 de agosto de 2020, con la Dirección de Redes Integradas de Salud Lima Sur, por un año, contado a partir de la fecha de su suscripción, que podrá ser renovado entre las partes, por periodos sucesivos de igual o menor duración, mediante actas de acuerdos entre los representantes de ambas instituciones (Andina, 2020b).

La llegada del cumplimiento de los doscientos años de independencia, sumado a lo acontecido en nuestro país con la pandemia, nos ha hecho reaccionar de manera tardía en entender la situación del peruano. Por más que en estos últimos veinte años, en cuanto a la salud mental se ha hecho muy poco, el interés por el bienestar de todos se hace presente. No obstante, queda en interrogante cómo dejar las secuelas de ciudadano falso, que aparenta lo ético y justo, que trata de sacar beneficios entre lo que dice y hace. En concreto, la herencia de factores negativos coloniales como la hipocresía, el encubrimiento y la mentira, llega a la clase política con muestras de negligencia y corrupción, lo que se toma como ejemplo muchas veces y nos dirige a la pérdida de identidad.

Por último, es necesario consolidar nuestra identidad de origen con la identidad universal, de carácter integrador de la educación y la cultura. A puertas del bicentenario aún tenemos promesas incumplidas en la agenda del 2030; igualmente, la salud mental en nuestro 
país ha tomado valor, aunque falta mucho por priorizar, pues ya se ha señalado que su carencia de atención nos ha llevado a la sociopatía. Esto se ve reflejado en las conductas irresponsables de las generaciones jóvenes respecto a la pandemia; es ahí donde el problema se muestra, donde la solución se está dando de manera lenta, con la mejora de los centros y la atención en la línea al 113, opción 5 . Como dice Palma (2006), se «ensalzó el bien y la libertad humana, tanto como execró el mal y la tiranía» (p. 101), pues el bienestar de cada peruano es prioridad, por ser derecho de ciudadano y deber del Estado.

Para entender mejor la identidad del peruano deben verse las influencias familiares, ambientales, educativas, socioeconómicas, culturales y políticas, y las garantías de un desarrollo psicoafectivo, sexual, emocional, laboral, de realización personal, ideológicas, éticas y religiosas. Se entiende que el patriotismo no solo es recordar nuestro pasado, sino vivir con satisfacción plena el ser peruanos, mirar hacia el futuro con el reconocimiento de nuestro pasado y presente, y trabajar en el legado de una salud mental, que es el mejor patrimonio que se pueda dar en las circunstancias que la pandemia ha traído y a puertas del bicentenario.

\section{REFERENCIAS}

Andina. Agencia Peruana de Noticias (2020a, 10 de octubre). Lanzan «Anímate Perú» para enfrentar problemas de salud mental surgidos en la pandemia. https://andina.pe/agencia/noticia-lanzan-animate-peru-para-enfrentar-problemas-salud-mental-surgidos-la-pandemia-817248.aspx

Andina. Agencia Peruana de Noticias (2020b, 13 de noviembre). Proyecto "Anímate Perú» fortalecerá la atención en salud mental en Lima Sur. https://andina.pe/agencia/noticia-proyecto-animateperu-fortalecera-atencion-salud-mental-lima-sur-821467.aspx 
Aramburú, C. y Mendoza, W. (2015). El futuro de la población peruana: problemas y oportunidades. Debates en Sociología, (41), 5-24. http://revistas.pucp.edu.pe/index.php/debatesensociologia/ article/view/14623

Basadre, J. (1958). La promesa de la vida peruana y otros ensayos. Juan Mejía Baca.

Defensoría del Pueblo (2019). El derecho a la salud mental. Supervisión de la implementación de la política pública de atención comunitaria y el camino a la desinstitucionalización. https://www.defensoria. gob.pe/wp-content/uploads/2018/12/Informe-Defensorial-N\%C2\%BA-180-Derecho-a-la-Salud-Mental-con-RD.pdf

Enterarse (2019, 10 de octubre). ¿Cuál es la situación de la salud mental en el Perú? Enterarse. https://www.enterarse.com/20191010_0001cual-es-la-situacion-de-la-salud-mental-en-el-peru

Organización Panamericana de la Salud (OPS) (2018). La carga de los trastornos mentales en la región de las Américas, 2018. https://iris. paho.org/bitstream/handle/10665.2/49578/9789275320280_spa. pdf? sequence $=9$ \&is Allowed $=y$

Palma, R. (2006). El médico inglés. Tradiciones peruanas. Octava y última serie. https://www.biblioteca.org.ar/libros/300830.pdf

Peña, S. (2011). El ser del peruano. Acta Médica Peruana, 28(2), 169-173. http://www.scielo.org.pe/scielo.php?script=sci_arttext\& pid $=$ S1728-59172011000300009

Stout, M. (2006). The Sociopath Next Door. Harmony.

Valdivia, G. (2020, 21 de agosto). Jorge Yamamoto: la mayoría de los peruanos tiene un serio problema de comportamiento. Andina. Agencia Peruana de Noticias. https://andina.pe/agencia/noticiajorge-yamamoto-mayoria-de-peruanos-tiene-un-serio-problemacomportamiento-810857.aspx 